\title{
"I could see, in the depth of his eyes, my own beauty reflected": Women's assortative preference for narcissistic, but not for Machiavellian or psychopathic male faces
}

\author{
Minna Lyons *, Alyson Blanchard \\ School of Psychology, University of Liverpool, United Kingdom
}

\section{A R T I C L E I N F O}

\section{Article history:}

Received 7 January 2016

Received in revised form 2 March 2016

Accepted 10 March 2016

Available online xxxx

Keywords:

Dark Triad

Assortative mating

Facial morphs

Mating context

\begin{abstract}
A B S T R A C T
Few studies have looked at assortative mating for the Dark Triad (i.e., Machiavellianism, psychopathy and narcissism), or assortative mating for facial characteristics related to personality. In two studies ( $n$ 's $=302$ and 262), we investigated whether women scoring high in the Dark Triad exhibited a preference for high and low Dark Triad male composite faces. In Study 1, using a two alternative forced-choice task and a short Dark Triad scale, there was little evidence for assortative mating. In Study 2, utilising a rating scale, longer personality measures, and controlling for perceptions of aggression, masculinity and dominance, we found positive assortative mating for narcissism in long-term relationships. Findings are discussed from evolutionary psychological perspective.
\end{abstract}

(c) 2016 Elsevier Ltd. All rights reserved.

\section{Introduction}

The term "assortative mating" refers to the tendency to seek out for mates who are similar on different characteristics, such as education (Krzyżanowska \& Mascie-Taylor, 2014), altruism (Tognetti, Berticat, Raymond, \& Faurie, 2014), and political orientation (Watson et al., 2004). Although the ultimate reasons for assortative mating in humans are not clear, there a few possibilities for why it does exist. For instance, similarity could be beneficial in promoting relationship stability (Luo \& Klohnen, 2005), crucial in bi-parental care of offspring. Another possibility is that assortative mating increases genetic similarity amongst family members, facilitating inclusive fitness via altruism (Thiessen \& Gregg, 1980). Indeed, phenotypic assortment seems to have an underlying genotypic assortment (Guo, Wang, Liu, \& Randall, 2014), which could even explain existence of variation in different characteristics (for narcissism, see Holtzman \& Donnellan, 2015). In the present study, we investigated assortative mating with regard to an aversive personality constellation, the Dark Triad. The Dark Triad traits share the core of selfish and exploitive inter-personal orientation, with some unique aspects specific to each trait, such as grandiosity (i.e., narcissism), cynicism (i.e., Machiavellianism), and callousness (i.e., psychopathy).

\footnotetext{
* Corresponding author at: University of Liverpool, School of Psychology, Bedford Street South, Liverpool L69 7ZA, United Kingdom.

E-mail address: m.lyons@liv.ac.uk (M. Lyons).
}

The Dark Triad has received significant interest since its conception over a decade ago (Paulhus \& Williams, 2002). Some of this research has focussed on mate choice for the Dark Triad characteristics, suggesting that the traits may either be aversive or desirable, depending on the mating context, methodology of the studies, and characteristics of the rater (e.g., Aitken, Lyons, \& Jonason, 2013; Carter, Campbell, \& Muncer, 2014; Dufner, Rauthmann, Czarna, \& Denissen, 2013; Lyons, Marcinkowska, Helle, \& McGrath, 2015; Marcinkowska, Helle, \& Lyons, 2015; Rauthmann \& Kolar, 2013). However, less is known about the Dark Triad in the context of assortative mating, especially during initial mate attraction. Studies investigating each trait separately have found positive assortative mating for narcissism in initial attraction, as well as in established relationships (Grosz, Dufner, Back, \& Denissen, 2015; Keller et al., 2014; Lamkin, Campbell, \& Miller, 2015). Others have found similarity in psychopathy and anti-social behaviour in initial attraction (Blanchard, Lyons, \& Centifanti, 2016) and in couples (Boutwell, Beaver, \& Barnes, 2012; Krueger, Moffitt, Caspi, Bleske, \& Silva, 1998; Savard, Brassard, Lussier, \& Sabourin, 2015). To our knowledge, only two studies to date have looked at all three Dark Triad traits together. Using a vignette design (Jonason, Lyons, \& Blanchard, 2015) and dating couples (Smith et al., 2014), these studies found positive assortment for psychopathy and Machiavellianism (Jonason et al., 2015; Smith et al., 2014), and negative assortative mating for narcissism (Smith et al., 2014). Thus, whether assortative mating preferences for especially narcissism exist is still unclear.

As well as being attracted to likeness in dating vignettes, it is possible that preference for similar levels of the Dark Triad 
is reflected in the choice for facial characteristics. Individual differences in extraversion, agreeableness, and conscientiousness (Little \& Perrett, 2007; Penton-Voak, Pound, Little, \& Perrett, 2006), aggressiveness (Carré, Morrissey, Mondloch, \& McCormick, 2010), socio-sexuality (Boothroyd, Jones, Burt, DeBruine, \& Perrett, 2008), as well as the Dark Triad (Holtzman, 2011) are reflected in the composite, static image of the face. Not only is the Dark Triad detectable in the face, but women also have a significant dislike for faces that have been computer-manipulated to reflect high and low levels of these traits (Lyons et al., 2015; Lyons \& Simeonov, 2016). This dislike appears to be influenced by individual differences in socio-sexuality and contraceptive use (Marcinkowska et al., 2015). Research has not yet looked at how an individual's Dark Triad traits relate to their choice of high or low Dark Triad facial morphs. In the present studies, we investigated whether women who are high on these traits show positive assortative mating for high Dark Triad men's faces.

Another important point of consideration is the impact of mating context on mating decisions. In evolutionary terms, women can enhance reproductive success in three ways; by obtaining good genes, support, and fathering from the male (Lu, Zhu, \& Chang, in press). It is thought that in short-term relationships, women seek, amongst other things, genetic benefits for their offspring, whereas in long-term relationships, provisioning and fathering ability may play a more important role (Lu et al., 2015). Evidence suggests that assortative mating for the Dark Triad is costly to relationship stability (Keller et al., 2014; Lamkin et al., 2015; Smith et al., 2014) and hence, have an adverse impact on bi-parental care. Thus, assortative mating for these traits in long-term relationships may not be a good strategy.

However, high Dark Triad males may be more profitable in shortterm relationships, perhaps by benefitting females in terms of gene capturing for their offspring. This could be especially important for high Dark Triad women who may be geared towards short-term relationships (Jonason \& Buss, 2012), which is also associated with preference for good gene indicators (Quist et al., 2012). Scant evidence points at narcissism as a potentially beneficial trait for women. A recent study found that preference for narcissistic male facial composites had an association with a higher number of offspring in women (Marcinkowska, Lyons, \& Helle, 2016), and other studies have demonstrated that narcissism has a link to attractiveness (Holtzman \& Strube, 2010), as well as to better physical and psychological health (Jonason, Baughman, Carter, \& Parker, 2015). Therefore, we would expect that out of the three Dark Triad traits, narcissistic women would prefer high narcissistic faces, especially in short-term relationships.

In summary, in two studies, we provide a unique contribution towards understanding how personality in women affects an initial attraction to male faces that are computer-manipulated to reflect the same personality traits. Because assortative mating for adverse personality traits has a negative influence on relationship stability, we do not necessarily expect to find assortative mating for the Dark Triad in the long-term mating context. However, high narcissistic women, with a short-term mating interest, may prefer high narcissistic men as casual partners, possibly due to genetic benefits associated with short-term mating.

\section{Study 1}

\subsection{Method}

\subsubsection{Participants}

A total of 302 women $\left(M_{\text {age }}=23.63, S D=8.19\right.$; age range 16-61) were recruited for a study on "Personality and Mate Choice" through advertising on social media, to a student population at a University in the UK, and on on-line participation websites. The first page of the survey contained a participant information sheet and an online consent form, and the last page had a full debrief.

\subsubsection{Materials}

2.1.2.1. Dark Triad facial morphs. Composite faces of high and low Dark Triad men were created using the Psychomorph software program (Tiddeman, Burt, \& Perrett, 2001), where prototype faces from Holtzman (2011) were imposed on five men's faces (Rantala et al., 2012) to create high and low narcissistic, Machiavellian, and psychopathic composites (see Lyons et al., 2015, for more detail and example faces). Preference for Machiavellian faces was correlated with preference for the psychopathic $(r(302)=.22 p<.001)$ but not the narcissistic $(r(302)=.09, p>.05)$ faces. Preference for psychopathic faces negatively correlated with preference for narcissistic faces $(r(302)=-.12, p=.05)$.

2.1.2.2. Short Dark Triad (SD3). The SD3 (Jones \& Paulhus, 2014) is a 27-item questionnaire that measures narcissism, Machiavellianism, and psychopathy (nine items each) on a 5-point Likert scale ( 1 = disagree strongly, $5=$ agree strongly). Participants indicated how much they agreed with statements such as "It's not wise to tell your secrets" (i.e., Machiavellianism; Cronbach's $\alpha=.77$ ), "People see me as a natural leader" (i.e., narcissism; $\alpha=71$ ) and "I like to get revenge on authorities" (i.e., psychopathy; $\alpha=.73$ ). The items were summed to form an index for each of the Dark Triad traits. Machiavellianism was positively correlated with narcissism $(r(302)=.31$, $p<.001)$ and psychopathy $(r(302)=.44, p<.001)$, and narcissism was correlated with psychopathy $(r(302)=.29, p<.001)$.

\subsubsection{Procedure}

Participants were randomly allocated to evaluate the Dark Triad facial morphs for desirability as either a short-term $(n=138)$ or a long-term $(n=164)$ partner (see Little, Cohen, Jones, \& Belsky, 2007 for a description of the mating context). Fifteen paired facial morphs were presented in a randomised order, each one consisting of high and low versions of Machiavellian, psychopathic and narcissistic faces (five pairs for each trait). Participants scored a point each time they chose a high face, resulting in continuous score between 0 (no choice for high face) and 1 (all choices for high face). Participants then completed the SD3.

\subsection{Results and discussion}

Table 1 shows the descriptive statistics, and one-sample t-test values (against a chance, 0.5 ) for the facial morph preference in both mating contexts. The results indicate that in any mating scenario women consider male faces high in the Dark Triad as undesirable. We calculated zero order correlation coefficients to test for assortative mating between the Dark Triad facial morphs and SD3 scores separately for short-term and long-term mating contexts. To account for multiple testing, we adjusted the alpha level to .01, which produced no significant correlations. The only near-significant correlation was between narcissism and short-term mating preference, indicating that

Table 1

Descriptive statistics and one-sample t-test values for facial morph preference.

\begin{tabular}{|c|c|c|c|c|}
\hline & \multicolumn{4}{|l|}{ Mean (SD) } \\
\hline & $\begin{array}{l}\text { Short-term } \\
\text { mating }\end{array}$ & $t$-Value & $\begin{array}{l}\text { Long-term } \\
\text { mating }\end{array}$ & $t$-Value \\
\hline \multicolumn{5}{|l|}{ Facial morphs } \\
\hline Machiavellianism & $.40(.21)$ & $-6.46^{* *}$ & $.41(.20)$ & $-7.41^{* *}$ \\
\hline Psychopathy & $.44(.24)$ & $-3.83^{* *}$ & $.45(.24)$ & $-3.83^{*}$ \\
\hline Narcissism & $.37(.25)$ & $-6.05^{* *}$ & $.32(.25)$ & $-9.47^{* *}$ \\
\hline
\end{tabular}

${ }^{*} p<.05$.

** $p<.01$. 
narcissistic women had a marginally higher preference for narcissistic facial morphs as short-term partners $(r=.17, p=.05)$. For brevity, the non-significant correlations are not reported here, but readers who are interested in the full findings, or in obtaining the data-file, are advised to contact the first author.

Our results show that women dislike high Dark Triad facial morphs across all mating contexts, and that there is little evidence for positive assortative mating for the faces. There was a trend towards positive assortative mating for narcissism in the short-term mating context, but the correlation did not quite reach significance with adjusted alpha values. Thus, the study would benefit from replication with another sample of women, and with longer measures for the Dark Triad.

It is clear that there is something aversive in these faces, as they were chosen less than would be expected by chance alone, a finding that was replicated from previous studies (e.g., Lyons et al., 2015; Lyons \& Simeonov, 2016). The Dark Triad traits are associated with potential for unprovoked aggression (Buckels, Jones, \& Paulhus, 2013), violence (Pailing, Boon, \& Egan, 2013) and sexual coercion (Jones \& Olderbak, 2014), which could be costly for women in reducing reproductive fitness. It is possible that the morphed faces somehow show this potential for danger. Therefore, we conducted a second study, asking women to rate the faces for perceived aggression, dominance, and masculinity, as well as for desirability as a long-term and short-term partner. We also looked at the assortative mating effect by using longer measures for the Dark Triad.

\section{Study 2}

\subsection{Method}

\subsubsection{Participants}

A total of 262 women were recruited for an on-line study on "Personality and Mate Choice" via an on-line participation website, a Crowdsourcing platform, and through advertising to a student population at a University in the UK. First page of the survey contained participant information and an on-line consent form, and the last page had a full debrief.

\subsubsection{Measures}

Participants ( $n=101, M_{\text {age }}=26.77, S D=11.51$; age range 18-60) who evaluated the Machiavellian faces filled in the 20-item, 7-point ( 1 = strongly disagree; $7=$ strongly agree) Mach IV scale (Christie \& Geis, 1970). Items included statements such as "Never tell anyone the real reason you did something unless it is useful to do so" and "It's hard to get ahead without cutting corners here and there". Items were summed to create an index of Machiavellianism $(\alpha=.80)$.

Participants ( $n=73, M_{\mathrm{age}}=21.00, S D=5.70$; age range 16-61) who evaluated the psychopathic faces filled in the 26-item, 4-point ( 1 = disagree strongly, 4 = agree strongly) Levenson's Self-Report Psychopathy Scale (LSRP; Levenson, Kiehl, \& Fitzpatrick, 1995). Items included statements such as "I often admire a really clever scam" and "I quickly lose interest in tasks I start". Items were summed to create an index of psychopathy $(\alpha=.81)$.

Participants ( $n=88, M_{\mathrm{age}}=24.52, S D=8.49$; age range $18-41$ ) who evaluated the narcissistic faces filled in the 40 -item forced- choice Narcissistic Personality Inventory (Raskin \& Terry, 1988). Items included forced-choice statements related to high (e.g., "I know that I am good because everybody keeps telling me so") and low narcissism (e.g., "When people compliment me I sometimes get embarrassed"). For each pair of questions, a score of 1 was given for a high narcissistic choice. The scores were summed to create a narcissism index $(\alpha=88)$.

The facial morphs were the same as in Study 1. The high and low version of each face was presented side by side, accompanied by a sliding scale ranging from -50 (strong choice for face on the left), 0 (no choice for either face), to +50 (strong choice for the face on the right). Participants were asked to choose the face that was more desirable as a (i) long-term partner, (ii) one-night stand, as well as the face that was more (iii) dominant, (iv) masculine, and (iv) aggressive. The evaluations of the five face pairs for summed together, and higher scores indicate a higher attribution of the trait to the high face.

\subsubsection{Procedure}

After completing demographic information, participants were randomly directed to evaluate either narcissistic, Machiavellian, or psychopathy faces. The high and low faces were counter-balanced so that sometimes the high face was presented on the right, and sometimes on the left hand side. Each participant evaluated the five face pairs for each trait five times (i.e., for aggressiveness, dominance, masculinity, desirability as a long-term partner, and a one-night stand). Following this, they filled in the respective Dark Triad measure, corresponding with the facial morph trait they evaluated.

\subsection{Results and discussion}

Table 2 shows the descriptive statistics and one-sample t-test values (against 0, which is no preference for either face) for ratings of the faces. Participants rated all of the high Dark Triad faces as less desirable partners than the low faces, with the exception of psychopathic faces in short-term relationships, where there was no preference for either face type. All of the high faces were rated as more aggressive than the low faces. The high Machiavellian and narcissistic faces were evaluated as more dominant and masculine than the low faces.

In order to assess the importance of perceived masculinity, aggression, dominance, and the participant's own Dark Triad traits (i.e., predictor variables) in ratings of the faces as long-term and short-term partners (i.e., outcome variables), we conducted a series of linear multiple regressions (see Tables 3-5). For the narcissistic faces, perceiving the faces as masculine was a positive predictor for desirability as a short term partner, and participant's high narcissism score, and perceiving the faces as low in aggressiveness were significant predictors as desirability as a long-term partner. We did not find assortative preferences for Machiavellian and psychopathic faces, but again, perceptions of the faces as low in aggressiveness was related to an increased preference as a long-term partner.

Interestingly, only narcissism was associated with an increased preference for narcissistic faces as long-term partners. Given the suggested co-evolution of narcissism and short-term mating strategies (Holtzman \& Strube, 2010), we would have expected assortative mating especially in the short-term mating context. Although our findings mirror a previous study on narcissism and assortative mating in established couples (e.g., Grosz et al., 2015), it contradicts research that has found positive assortative mating for psychopathy and Machiavellianism, but not for narcissism (Jonason et al., 2015; Smith et al., 2014).

\section{Discussion}

In two studies, we investigated the relationship between women's Dark Triad traits, and their preference for male faces characterised by the same traits. In Study 1, using a short measure for the Dark Triad, we did not find evidence for assortative mating. In Study 2, we found

Table 2

Descriptive statistics and one-sample t-test (against 0) values for facial morphs.

\begin{tabular}{lccc}
\hline & \multicolumn{3}{l}{ Mean (SD) } \\
\cline { 2 - 4 } & Machiavellian & Psychopathy & \multicolumn{1}{l}{ Narcissism } \\
\hline Dominant & $4.06(10.51)^{* *}$ & $-0.41(11.38)$ & $4.30(13.22)^{*}$ \\
Aggressive & $6.74(8.30)^{* *}$ & $6.11(10.96)^{* *}$ & $5.57(11.47)^{* *}$ \\
Masculine & $3.25(10.29)^{* *}$ & $-1.18(10.71)$ & $4.41(11.81)^{* *}$ \\
Short-term partner & $-4.58(8.14)^{* *}$ & $-1.79(8.27)$ & $-7.60(8.67)^{* *}$ \\
Long-term partner & $-4.64(7.16)^{* *}$ & $-2.86(8.59)^{*}$ & $-8.67(10.77)^{* *}$ \\
\hline
\end{tabular}

$* p<.01$,

** $p<.001$. 
Table 3

Regression model for participant narcissism, perceptions of dominance, aggression, and masculinity (predictors), and the ratings of narcissistic faces as short-term and long-term partners (outcome variables).

\begin{tabular}{llcc}
\hline Mating context & Predictor & \multicolumn{1}{c}{ t } & \multicolumn{1}{c}{0.06} \\
\hline \multirow{2}{*}{ Short term } & Narcissism & 0.59 & 0.14 \\
& Dominant & 0.98 & -0.13 \\
& Aggressive & -1.9 & $.39^{*}$ \\
Long term & Masculine & 2.28 & $.22^{*}$ \\
& Narcissism & 2.02 & 0.19 \\
& Dominant & 1.36 & $-.46^{* *}$ \\
& Aggressive & -2.84 & 0.17 \\
\hline
\end{tabular}

$* p<.05$

** $p<.01$.

some evidence for positive assortative mating for narcissism in longterm relationships. Interestingly, out of the Dark Triad traits, narcissism is more strongly associated with short-term mating interests than psychopathy or Machiavellianism (Jonason, Luevano, \& Adams, 2012), and narcissistic women exhibit lower relationship commitment (e.g., Foster, Shrira, \& Campbell, 2006), which could result in a preference for faces that show an indication of genetic quality (see also Quist et al., 2012). It is possible that narcissistic women have a long-term preference for narcissistic men for the same reason as attractive women have a long-term preference for masculine men (e.g., Feinberg et al., 2012). Women may gain benefits (e.g., genes, support, resources) from narcissistic males, but only if their own traits (e.g., narcissism) mitigate the costs associated with being in a relationship with a narcissistic man. Future studies should investigate whether the assortative choice for narcissistic male faces is a combination of a short-term mating interest of high narcissistic women, and indicators of good genes by high narcissist men.

One pending question is what the morphometric characteristics in these faces are that women use as a cue to guide their preferences. At the moment it is not clear how the Dark Triad faces differ from each other, and which dimensions of the face associate with the Dark Triad traits (see also Holtzman, 2011; Lyons et al., 2015). All of the high faces were perceived as aggressive, and the narcissistic and Machiavellian faces were perceived as masculine and dominant. Whether these characteristics relate to other morphometric dimensions of the faces associated with dominance and aggression (e.g., facial width; Lefevre, Etchells, Howell, Clark, \& Penton-Voak, 2014) remains to be addressed in future studies.

Our study does have some limitations. Mate choice is complex, and it would be useful to investigate assortative mating for Dark Triad in more realistic interactions, for example, utilising speed-dating events. Methodological differences between the two studies (i.e., forced-choice vs rating scale; short vs long psychometric measures for the Dark Triad) could have led to slightly different findings. We recommend the use of longer measures whenever possible, as these may better capture the Dark Triad traits of the rater. Further, taking the "replication crisis" in

Table 4

Regression model for participant Machiavellianism, perceptions of dominance, aggression, and masculinity (predictors), and the ratings of Machiavellian faces as short-term and long-term partners (outcome variables)

\begin{tabular}{llrc}
\hline Mating context & Predictor & \multicolumn{1}{c}{ t } & \multicolumn{1}{c}{$\beta$} \\
\hline Short term & Machiavellianism & 1.82 & 0.18 \\
& Dominant & -1.57 & -0.2 \\
& Aggressive & -1.31 & -0.16 \\
Long term & Masculine & 0.83 & 0.09 \\
& Machiavellianism & 1.21 & $0.12^{*}$ \\
& Dominant & 1.32 & 0.17 \\
& Aggressive & -3.86 & $-.47^{* *}$ \\
& Masculine & 1.03 & 0.11 \\
\hline
\end{tabular}

$* p<.05$.

** $p<.01$.
Table 5

Regression model for participant psychopathy, perceptions of dominance, aggression, and masculinity (predictors), and the ratings of psychopathy faces as short-term and long-term partners (outcome variables).

\begin{tabular}{llrc}
\hline Mating context & Predictor & \multicolumn{1}{l}{ t } & $\beta$ \\
\hline Short term & Psychopathy & 0.88 & -0.11 \\
& Dominant & 0.81 & -0.11 \\
& Aggressive & -0.81 & -0.1 \\
Long term & Masculine & 0.98 & 0.13 \\
& Psychopathy & -0.35 & $-0.04^{*}$ \\
& Dominant & -1.09 & 0.13 \\
& Aggressive & -3.11 & $-.36^{* *}$ \\
& Masculine & 0.98 & -0.12 \\
\hline
\end{tabular}

${ }^{*} p<.05$.

*** $p<.01$.

psychology (Bohannon, 2015), we would like to see a replication of these results by another research team, as well as in a non-Western culture. Finally, the high prototype facial morphs exhibited only moderate levels of the Dark Triad traits (Holtzman, 2011), and it is possible that having facial morphs from more extreme ends of the scales would provide different results in terms of assortative mating.

In conclusion, we have provided the first evidence for assortative mating for Dark Triad facial characteristics. Our findings suggest that although overall, the Dark Triad faces are considered as aversive, narcissistic women show less aversion towards narcissistic male faces in the long-term mating context. Future research would benefit from investigating assortative mating for the Dark Triad in more ecologically valid settings, which would be crucial for understanding attraction between toxic personalities.

\section{References}

Aitken, S. J., Lyons, M., \& Jonason, P. K. (2013). Dads or cads? Women's strategic decisions in the mating game. Personality and Individual Differences, 55, 118-122.

Blanchard, A., Lyons, M., \& Centifanti, L. (2016). An effective way to deal with predators is to taste terrible: Primary and secondary psychopathy and mate preference. Personality and Individual Differences, 92, 128-134.

Bohannon, J. (2015). Many psychology papers fail replication test. Science, 349, 910-911. Boothroyd, L. G., Jones, B. C., Burt, D. M., DeBruine, L. M., \& Perrett, D. I. (2008). Facial correlates of sociosexuality. Evolution and Human Behavior, 29, 211-218.

Boutwell, B. B., Beaver, K. M., \& Barnes, J. C. (2012). More alike than different: Assortative mating and antisocial propensity in adulthood. Criminal Justice and Behavior, 39(9), 1240-1254.

Buckels, E. E., Jones, D. N., \& Paulhus, D. L. (2013). Behavioral confirmation of everyday sadism. Psychological Science, 24, 2201-2209.

Carré, J. M., Morrissey, M. D., Mondloch, C. J., \& McCormick, C. M. (2010). Estimating aggression from emotionally neutral faces: Which facial cues are diagnostic? Perception, 39, 356-377.

Carter, G. L., Campbell, A. C., \& Muncer, S. (2014). The dark triad personality: Attractiveness to women. Personality and Individual Differences, 56, 57-61.

Christie, R., \& Geis, F. L. (1970). Studies in Machiavellianism. New York: Academic Press.

Dufner, M., Rauthmann, J. F., Czarna, A. Z., \& Denissen, J. J. (2013). Are narcissists sexy? Zeroing in on the effect of narcissism on short-term mate appeal. Personality and Social Psychology Bulletin, 39, 870-882.

Feinberg, D. R., DeBruine, L. M., Jones, B. C., Little, A. C., O'Connor, J. J., \& Tigue, C. C. (2012). Women's self-perceived health and attractiveness predict their male vocal masculinity preferences in different directions across short-and long-term relationship contexts. Behavioral Ecology and Sociobiology, 66, 413-418.

Foster, J. D., Shrira, I., \& Campbell, W. K. (2006). Theoretical models of narcissism, sexuality, and relationship commitment. Journal of Social and Personal Relationships, 23, 367-386

Grosz, M. P., Dufner, M., Back, M. D., \& Denissen, J. J. (2015). Who is open to a narcissistic romantic partner? The roles of sensation seeking, trait anxiety, and similarity. Journal of Research in Personality, 58, 84-95.

Guo, G., Wang, L., Liu, H., \& Randall, T. (2014). Genomic assortative mating in marriages in the United States. PloS One, 9(11), e112322.

Holtzman, N. S. (2011). Facing a psychopath: Detecting the dark triad from emotionally neutral faces, using prototypes from the Personality Faceaurus. Journal of Research in Personality, 45, 648-654.

Holtzman, N. S., \& Donnellan, M. B. (2015). The roots of Narcissus: Old and new models of the evolution of narcissism. In V. Zeigler-Hill, L. L. M. Welling, \& T. K. Shackelford (Eds.), Evolutionary perspectives on social psychology (pp. 479-489). New York: Springer.

Holtzman, N. S., \& Strube, M. J. (2010). Narcissism and attractiveness. Journal of Research in Personality, 44, 133-136. 
Jonason, P. K., \& Buss, D. M. (2012). Avoiding entangling commitments: Tactics for implementing a short-term mating strategy. Personality and Individual Differences, 52, 606-610.

Jonason, P. K., Baughman, H. M., Carter, G. L., \& Parker, P. (2015). Dorian Gray without his portrait: Psychological, social, and physical health costs associated with the Dark Triad. Personality and Individual Differences, 78, 5-13.

Jonason, P. K., Luevano, V. X., \& Adams, H. M. (2012). How the Dark Triad traits predict relationship choices. Personality and Individual Differences, 53, 180-184.

Jonason, P. K., Lyons, M., \& Blanchard, A. (2015). Birds of a "bad" feather flock together: The Dark Triad and mate choice. Personality and Individual Differences, 78, 34-38.

Jones, D. N., \& Olderbak, S. G. (2014). The associations among dark personalities and sexual tactics across different scenarios. Journal of Interpersonal Violence, 29, 1050-1070.

Jones, D. N., \& Paulhus, D. L. (2014). Introducing the Short Dark Triad (SD3): A brief measure of dark personality traits. Assessment, 21, 28-41.

Keller, P. S., Blincoe, S., Gilbert, L. R., Dewall, C. N., Haak, E. A., \& Widiger, T. (2014). Narcissism in romantic relationships: A dyadic perspective. Journal of Social and Clinical Psychology, 33, 25-50.

Krueger, R. F., Moffitt, T. E., Caspi, A., Bleske, A., \& Silva, P. A. (1998). Assortative mating for antisocial behavior: Developmental and methodological implications. Behavior Genetics, 28, 173-186.

Krzyżanowska, M., \& Mascie-Taylor, C. N. (2014). Educational and social class assortative mating in fertile British couples. Annals of Human Biology, 41, 561-567.

Lamkin, J., Campbell, W. K., \& Miller, J. D. (2015). An exploration of the correlates of grandiose and vulnerable narcissism in romantic relationships: Homophily, partner characteristics, and dyadic adjustment. Personality and Individual Differences, 79, 166-171.

Lefevre, C. E., Etchells, P. J., Howell, E. C., Clark, A. P., \& Penton-Voak, I. S. (2014). Facial width-to-height ratio predicts self-reported dominance and aggression in males and females, but a measure of masculinity does not. Biology Letters, 10(10), 20140729.

Levenson, M. R., Kiehl, K. A., \& Fitzpatrick, C. M. (1995). Assessing psychopathic attributes in a noninstitutionalized population. Journal of Personality and Social Psychology, 68, 151-158.

Little, A. C., \& Perrett, D. I. (2007). Using composite images to assess accuracy in personality attribution to faces. British Journal of Psychology, 98, 111-126.

Little, A. C., Cohen, D. L., Jones, B. C., \& Belsky, J. (2007). Human preferences for facial masculinity change with relationship type and environmental harshness. Behavioral Ecology and Sociobiology, 61, 967-973.

Lu, H. J., Zhu, X. Q., \& Chang, L. (2015). Good genes, good providers, and good fathers: Economic development involved in how women select a mate. Evolutionary Behavioral Sciences, 9, 215-228.

Luo, S., \& Klohnen, E. C. (2005). Assortative mating and marital quality in newlyweds: A couple-centered approach. Journal of Personality and Social Psychology, 88, 304-326.

Lyons, M., \& Simeonov, L. (2016). The undesirable Dark Triad? Women dislike Dark Triad male faces across different mating context and socio-ecological conditions. Personality and Individual Differences, 90, 338-341.
Lyons, M. T., Marcinkowska, U. M., Helle, S., \& McGrath, L. (2015). Mirror, mirror, on the wall, who is the most masculine of them all? The Dark Triad, masculinity, and women's mate choice. Personality and Individual Differences, 74, 153-158.

Marcinkowska, U. M., Helle, S., \& Lyons, M. T. (2015). Dark traits: Sometimes hot, and sometimes not? Female preferences for Dark Triad faces depend on sociosexuality and contraceptive use. Personality and Individual Differences, 86, 369-373.

Marcinkowska, U. M., Lyons, M. T., \& Helle, S. (2016). Women's reproductive success and the preference for Dark Triad in men's faces. Evolution and Human Behavior.

Pailing, A., Boon, J., \& Egan, V. (2013). Personality, the Dark Triad and violence. Personality and Individual Differences, 67, 81-86.

Paulhus, D. L., \& Williams, K. M. (2002). The dark triad of personality: Narcissism, Machiavellianism, and psychopathy. Journal of Research in Personality, 36, 556-563.

Penton-Voak, I. S., Pound, N., Little, A. C., \& Perrett, D. I. (2006). Personality judgments from natural and composite facial images: More evidence for a "kernel of truth" in social perception. Social Cognition, 24, 607-640.

Quist, M. C., Watkins, C. D., Smith, F. G., Little, A. C., DeBruine, L. M., \& Jones, B. C. (2012) Sociosexuality predicts women's preferences for symmetry in men's faces. Archives of Sexual Behavior, 41, 1415-1421.

Rantala, M. J., Moore, F. R., Skrinda, I., Krama, T., Kivleniece, I., Kecko, S., \& Krams, I. (2012). Evidence for the stress-linked immunocompetence handicap hypothesis in humans. Nature Communications, 3, 694.

Raskin, R., \& Terry, H. (1988). A principal-components analysis of the Narcissistic Personality Inventory and further evidence of its construct validity. Journal of Personality and Social Psychology, 54, 890-902.

Rauthmann, J. F., \& Kolar, G. P. (2013). The perceived attractiveness and traits of the Dark Triad: Narcissists are perceived as hot, Machiavellians and psychopaths not. Personality and Individual Differences, 54, 582-586.

Savard, C., Brassard, A., Lussier, Y., \& Sabourin, S. (2015). Subclinical psychopathic traits and romantic attachment in community couples: A dyadic approach. Personality and Individual Differences, 72, 128-134.

Smith, C. V., Hadden, B. W., Webster, G. D., Jonason, P. K., Gesselman, A. N., \& Crysel, L. C. (2014). Mutually attracted or repulsed? Actor-partner interdependence models of Dark Triad traits and relationship outcomes. Personality and Individual Differences, 67, 35-41.

Thiessen, D., \& Gregg, B. (1980). Human assortative mating and genetic equilibrium: An evolutionary perspective. Ethology and Sociobiology, 1, 111-140.

Tiddeman, B., Burt, M., \& Perrett, D. (2001). Prototyping and transforming facial textures for perception research. IEEE Computer Graphics and Applications, 21, 42-50.

Tognetti, A., Berticat, C., Raymond, M., \& Faurie, C. (2014). Assortative mating based on cooperativeness and generosity. Journal of Evolutionary Biology, 27, 975-981.

Watson, D., Klohnen, E. C., Casillas, A., Nus Simms, E., Haig, J., \& Berry, D. S. (2004). Match makers and deal breakers: Analyses of assortative mating in newlywed couples. Journal of Personality, 72, 1029-1068. 